\title{
Hypericum spp.-An Overview of the Extraction Methods and Analysis of Compounds
}

\author{
Valentin Ion ${ }^{1}$, Irina Ielciu ${ }^{2, *}$ (]) Anca-Gabriela Cârje ${ }^{1}$, Daniela Lucia Muntean ${ }^{1}$, Gianina Crişan ${ }^{2,+}$ \\ and Ramona Păltinean ${ }^{2,+}$
}

Citation: Ion, V.; Ielciu, I.; Cârje, A.-G.; Muntean, D.L.; Crişan, G.; Păltinean, R. Hypericum spp.-An Overview of the Extraction Methods and Analysis of Compounds. Separations 2022, 9, 17. https:// doi.org/10.3390/separations 9010017 Academic Editors: Daniele Naviglio and Federica Bianchi

Received: 11 December 2021

Accepted: 11 January 2022

Published: 14 January 2022

Publisher's Note: MDPI stays neutral with regard to jurisdictional claims in published maps and institutional affiliations.

Copyright: (C) 2022 by the authors. Licensee MDPI, Basel, Switzerland. This article is an open access article distributed under the terms and conditions of the Creative Commons Attribution (CC BY) license (https:// creativecommons.org/licenses/by/ $4.0 /)$.
1 Department of Analytical Chemistry and Drug Analysis, Faculty of Pharmacy, "George Emil Palade" University of Medicine, Pharmacy, Science and Technology, 540142 Targu Mures, Romania; valentin.ion@umfst.ro (V.I.); anca.carje@umfst.ro (A.-G.C.); daniela.muntean@umfst.ro (D.L.M.)

2 Department of Pharmaceutical Botany, Faculty of Pharmacy, "Iuliu Haţieganu" University of Medicine and Pharmacy, 400010 Cluj-Napoca, Romania; gcrisan@umfcluj.ro (G.C.); rpaltinean@umfcluj.ro (R.P.)

* Correspondence: irina.ielciu@umfcluj.ro

+ These authors contributed equally to this work.

\begin{abstract}
The Hypericum genus contains one of the few genera of flowering plants that contains a species with authorization for marketing as a traditional medicine, H. perforatum. Due to the fact that this is a large genus, comprising numerous species, a large amount of interest has been shown over the years in the study of its various pharmacological activities. The chemical composition of these species is quite similar, containing compounds belonging to the class of phloroglucinol derivatives, naphthodianthrones, phenols, flavonoids and essential oils. Taking all of this into consideration, the present study aims to offer an overview of the species of the genus from the point of view of their extraction techniques and analysis methods. An extensive study on the scientific literature was performed, and it revealed a wide range of solvents and extraction methods, among which ethanol and methanol, together with maceration and ultrasonication, are the most frequent. Regarding analysis methods, separation and spectral techniques are the most employed. Therefore, the present study provides necessary data for future studies on the species of the genus, offering a complete overview and a possible basis for their development.
\end{abstract}

Keywords: Hypericum spp.; solvents; extraction methods; separation methods; spectral methods

\section{Introduction}

The genus Hypericum, belonging to the Hypericaceae family, comprises more than 500 species which are included in 36 sections [1-4]. These species can be found naturally in different areas, especially in the temperate climate, being absent in extreme environmental conditions $[3,5,6]$. They can be found as small shrubs and herbs, having opposite leaves, with transparent or black points, yellow flowers arranged in cymose inflorescences, with five sepals and five petals, numerous stamens, and an ovary with one to five ovarian cavities [7].

Despite the fact that there is a large number of Hypericum species, only H. perforatum L. (St. John's wort) has been intensively investigated, both chemically and pharmacologically, being considered as a model species for the genus $[2,4,5]$. The species has a monograph in the European Pharmacopoeia [8] and in the European Medicines Agency monographs [9], and it has been extensively studied over the years for its pharmacological activities [5]. The vegetal medicinal product consists of the aerial dried parts, harvested during the flowering period $[2,10]$. The chemical composition of different Hypericum species may be variable depending on pedoclimatic conditions [10].

Hypericum species represent widely known traditional healing agents, used for the treatment of numerous pathologies [5]. Several species are used for different dermatological issues such as burns or injuries, or for their antidepressant, antimicrobial or anti- 
inflammatory properties [4,6]. Compounds that are responsible for the biological activities belong to the class of phloroglucinol derivatives (e.g., hyperforins), naphthodianthrones (e.g., hypericins), phenols (e.g., chlorogenic acid), flavonoids (e.g., hyperoside, rutoside, quercetin) and essential oils $[3,4,10,11]$. In addition, tannins, procyanidins, phenylpropanes, xanthones and volatile compounds have been identified [11]. The chemical composition of the Hypericum genus can nevertheless be very different between species [4].

The officinal species, $H$. perforatum, has been used for centuries, being one of the most popular herbal remedies in traditional medicine. It has been used in different forms (e.g., ointments, tinctures, drops) [11] for the treatment of ulcers and other gastrointestinal disorders, diabetes mellitus, cold and flu, jaundice and other hepatic and biliary disorders, hemoptysis, hematemesis, metrorrhagia, traumatic hemorrhage, irregular menstruation, acute mastitis, swelling and pain of the eye, urinary tract infection, sore furuncle, burns, wounds and bruises and rheumatic arthritis [12,13]. Based on these traditional uses, among the most studied uses are the wound healing and anti-inflammatory activities related to skin conditions, which can be directly linked to antioxidant and anti-aging properties [12,14]. Other reported activities are the antibacterial [15], antimitogenic, antiviral, photodynamic, antitumor, antioxidant and analgesic effects $[5,12,13,16]$. It is especially known for its antidepressant activity [3,11]; mechanisms that are involved in this activity are related to the inhibition of monoamine oxidase, the inhibition of synaptosomal reuptake of amines, the effects on monoamine transporters and the effects on serotonin receptors, which are due to hypericin, hyperforin or to the polycyclic polyprenylated acylphloroglucinols $[17,18]$. Due to its therapeutical properties, the species and its derived pharmaceutical products are currently among the most used and consumed vegetal products in the world [10,11]. It is the only species of the genus that has marketing authorization as a traditional medicine in several European countries [19]. There are numerous phytotherapeutical products containing the aerial part of the species or its dry extracts $[8,9]$ that are available on the market all over the world, some of them being protected by patents, such as Prosoft ${ }^{\circledR} 300 \mathrm{mg}$ (from R\&D Pharma company, Monaco, Europe), which is indicated for the treatment of moderate depression, Hyperoil ${ }^{\circledR}$ (from RI.MOS. srl. Company, Mirandola, Italy), which is available in Europe and promotes wound healing of chronic and acute lesions, the Wound and 1-Primary Wound Dressing, indicated for the treatment of skin defects associated with skin disorders or some cosmetic formulations (from the Amore Pacific Corp., Seoul, South Korea) indicated as anti-aging agents or for skin exfoliation, maintenance of the barrier function of the skin, inhibition of inflammatory mediators, wound healing, protection against UV, epidermal regeneration and inhibition of tyrosinase, collagenase or elastase (e.g., Crodarom ${ }^{\circledR}$ ST John's Wort O produced by Crodarom S.A.S./CRODA, Chanac, France) [3,12].

The current taxonomical classification for the Hypericum genus is performed by comparing the morphology of flowers and other vegetative organs, but pedoclimatic conditions may lead to incorrect identification [1]. In order to establish the identity of these species and for avoiding uncertainties, it appears absolutely important to complement these at least with phytochemical analysis and sometimes even with molecular data [2]. Another reason for the correct analysis of herbal products belonging to the Hypericum genus is related to the establishment of their safety and toxicity. The vast majority of the existing studies concerning the toxicity of extracts or isolated compounds from these species are related to cell viability determination after exposure, and report significantly deficient data, due to the lack of relevant pharmacological or toxicological approaches [12]. However, Hypericum extracts' and phytotherapeutical remedies' side effects are considered to be mild and rare, when they are consumed in moderation [8,9]. Nevertheless, further toxicity studies are needed in order to establish the effects of administration or application of Hypericum vegetal products or extracts. Only the officinal species, H. perforatum, has been the subject of such toxicity studies to determine its safe use as vegetal medicinal product for different purposes $[9,12]$, while the toxicological approaches of other species are yet to be studied and determined. Their lack in scientific literature represents an important matter to be considered in future studies of these species [12]. An important point regarding 
the toxicity and pharmacological effects of $H$. perforatum involve induction of enzymes by its extracts. Plant-drug interactions or extract-drug interactions are highly reported in the literature. The molecules responsible for this kind of interactions are hyperforins and hypericins. Hyperforins have proven to be potent cytochrome (CYP) enzyme (members of the microsomal family) inducers, especially cytochrome P 450 and even P-glycoprotein inducers. Since many available drugs such as anticoagulants, anti-HIV drugs, antidepressants, antimicrobial drugs, anticonvulsants or oral contraceptives are substrates for CYP enzymes, the inductive effect may trigger the loss of the therapeutic effect of several active pharmaceutical ingredients [13].

Taking all of this into consideration, Hypericum spp. appear as important vegetal medicinal products and have significant potential for further studies that may bring evidence to support their traditional uses or may offer supplementary details on different biological activities and their correspondent mechanisms of action, which are studied but still need more scientific arguments. The high complexity of the genus is a strong reason for the lack of reviews. Existing studies offer specific evaluations on different aspects related to the genus, such as their cosmeceutical applications [12], their specific classes of compounds (e.g., flavonoids) [4], their genetic phytochemical profiling [2] or they offer an overview of their ethnobotany, phytochemical composition and pharmacological properties [6]. As the species of the genus represent important vegetal medicinal products, the interest towards their study is growing, especially as it presents a large number of species that may present similar activities to the officinal species [2,6]. To the best of our knowledge, there are no studies examining the methods of extraction and analysis of phytochemical compounds, which may represent the basis of developing future possible studies on the species of the genus.

Therefore, the main aim of the present study is to provide an overview of the main extraction and analysis methods used over the last decade for biologically active compounds of high interest from different species belonging to the genus Hypericum. Secondly, this study was also designed to be an important tool and to represent a starting point for researchers that wish to undertake further, new studies that may be focused on: extraction processes' optimizations; development, improvement and standardization of analytical methods; characterization of new or unstudied species; studies regarding the influence of external or internal factors on the composition of the secondary metabolic compounds. Thirdly, the study provides a synthesis of relevant information for the aforementioned aims, both in the form of an overview and also under a more specific and exhaustive form using Supplementary Materials, taking into consideration the relatively increased number of articles reviewed. In this way, by offering an evaluation and a summarization of these aspects, we may provide the necessary scientific arguments and the background for increasing the existing scientific information on these species. Finally, the novelty and originality of the present study rely on the fact that it represents one of the very few approaches in the literature capable to integrate relatively high quantity and updated data related to the extraction methods and analytical methods used for analysis of compounds derived from Hypericum genus, all due to the increased number of articles and the heterogeneity of the data.

\section{Materials and Methods}

\subsection{Data Obtention}

In order to construct the overview of the main extraction techniques and the main methods used for the analysis of compounds of Hypericum genus, a survey of the scientific databases (PubMed, Science Direct, Google Scholar, Web of Science) was performed. A period of search was established (2010-2021) and the keywords "Hypericum" and "Hypericum genus" were used. The keyword "Hypericum" returned more than 8000 results, while "Hypericum genus" more than 2000, "Hypericum extraction" more than 2500 and "Hypericum analysis" more than 6000. Narrowing the research for the selected interval resulted in 4500 , 1200,1600 and 3800 results. Among all these, only 102 were considered to be relevant for 
the purpose of the study and analyzed further in order to construct the following sections of the present review.

\subsection{Data Analysis}

After obtaining the results of the performed searches, the articles were sorted by year and subject. Selection was evaluated after selection based on their content, using the following criteria:

- Methods of extraction;

- Analysis methods.

Articles discussing these aspects for the officinal species were taken into consideration, as it represents the model species. Regarding other Hypericum species, articles were taken into consideration if they evaluated at least two different species. For articles discussing individual species, only articles that were relevant in their content were considered.

\section{Results and Discussion}

\subsection{Extraction Methods}

Due to the fact that the chemical composition of Hypericum species is large and may be included in a wide range of compounds, it appears to be very difficult to obtain their profiling only by using a single extraction method and a single solvent [4]. The extraction of compounds is very different, depending on the extraction conditions (temperature, solvent concentration, duration), but also on the method. All these may impact the bioactive properties of the obtained extract [10]. Moreover, the content of bioactive compounds may also vary depending on the vegetal product (flowers, leaves, aerial parts), but also on the pedoclimatic conditions $[4,10]$.

\subsubsection{Extraction Solvents}

The most frequently used solvents were pure ethanol and methanol, but it appeared that their mixing with water may be even more efficient [4]. Different extraction solvents together with compounds specific for these solvents can be found in Table 1.

Table 1. Different solvents used for extraction of compounds in the composition of Hypericum spp.

\begin{tabular}{|c|c|c|c|}
\hline Vegetal Material & Solvent & Compounds & Reference \\
\hline H. perforatum aerial parts & $50 \%$ Aqueous ethanol & $\begin{array}{l}\text { Quercetin derivatives (rutin, hyperoside, } \\
\text { isoquercitrin, quercetrin), protocatechuic } \\
\text { acid, (-)-epicatechin, I3, II8-biapigenin } \\
\text { and chlorogenic acid derivatives, } \\
\text { naphthodianthrones and } \\
\text { phloroglucinols (hyperforin, } \\
\text { adhyperforin, hypericin, } \\
\text { pseudohypericin and furohyperforin }\end{array}$ & {$[20]$} \\
\hline $\begin{array}{c}\text { H. perforatum, } H \text {. annula- } \\
\text { tum aerial parts }\end{array}$ & $60 \%$ Aqueous ethanol & Hypericin, epicatechin, and rutin & {$[4]$} \\
\hline H. perforatum leaves & $80 \%$ Aqueous ethanol & $\begin{array}{l}\text { Polysaccharides, hypericin, hyperforin, } \\
\text { hyperoside, quercetin, quercitrin, rutin }\end{array}$ & {$[21,22]$} \\
\hline H. przewalskii aerial parts & $\begin{array}{l}\text { 95\% Aqueous ethanol, followed by } \\
\text { partitioning between } \mathrm{CH}_{2} \mathrm{Cl}_{2} \text {, ethyl } \\
\text { acetate and n-butanol }\end{array}$ & $( \pm)$-hyperzewalsins A-D & [23] \\
\hline H. perforatum aerial parts & $\begin{array}{l}\text { 95\% Aqueous ethanol, followed by } \\
\text { partitioning between } \mathrm{CH}_{2} \mathrm{Cl}_{2} \\
\text { petroleum ether and acetone }\end{array}$ & Hyperforatins L-U & [24] \\
\hline H. perforatum aerial parts & $\begin{array}{l}95 \% \text { Aqueous ethanol, } \% \text {, followed } \\
\text { by partitioning between } \mathrm{CH}_{2} \mathrm{Cl}_{2} \\
\text { petroleum ether and acetone }\end{array}$ & $\begin{array}{l}\text { Polycyclic polyprenylated } \\
\text { acylphloroglucinols }\end{array}$ & [25] \\
\hline $\begin{array}{c}\text { H. perforatum } \\
\text { aerial parts / Hypericum spp. } \\
\text { aerial parts }\end{array}$ & 96\% Aqueous ethanol & $\begin{array}{l}\text { Flavonoids and polyphenols: } \\
\text { chlorogenic acid, rutin, hyperoside, } \\
\text { quercetin, quercitrin }\end{array}$ & {$[10,26,27]$} \\
\hline
\end{tabular}


Table 1. Cont.

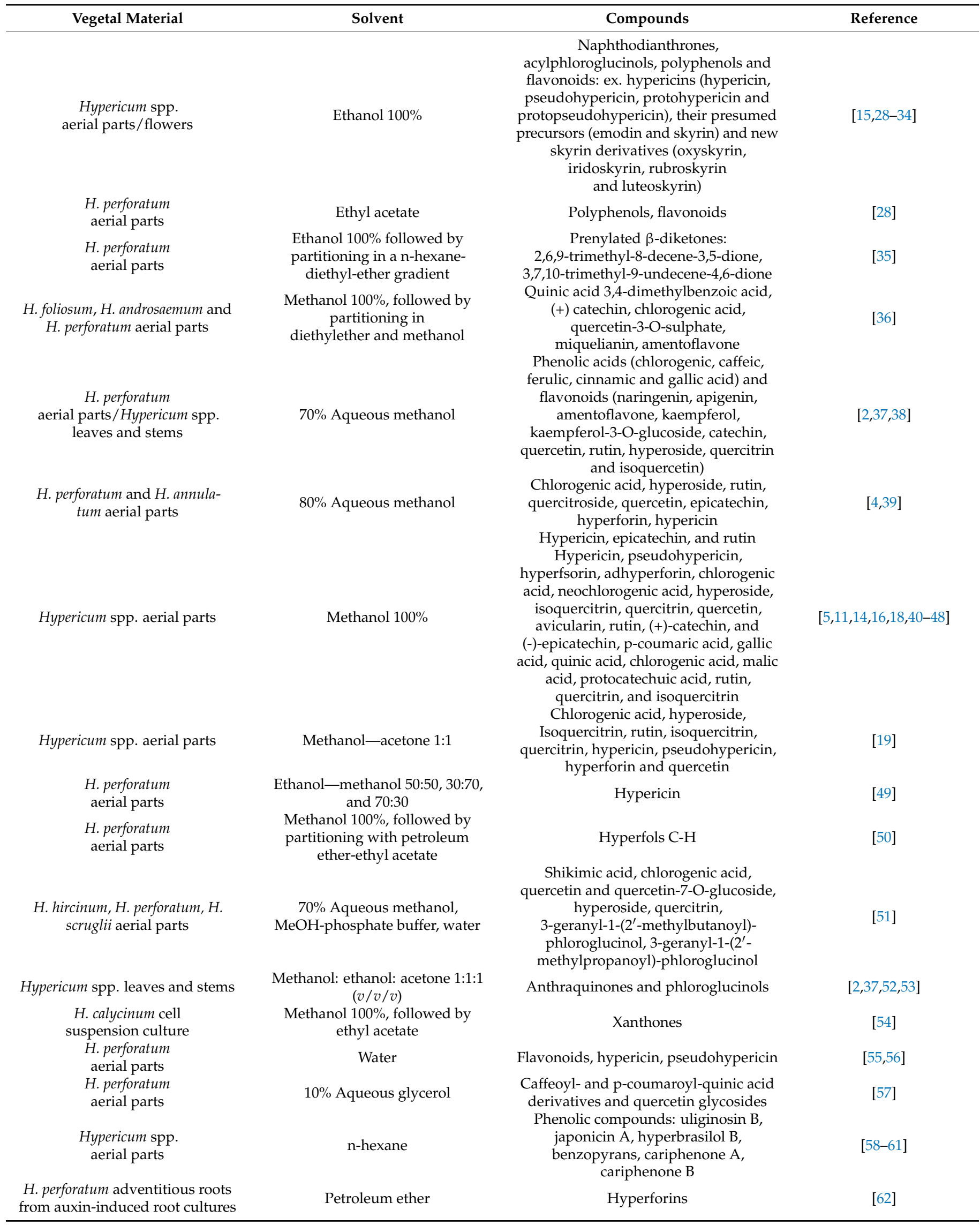


Table 1. Cont.

\begin{tabular}{|c|c|c|c|}
\hline Vegetal Material & Solvent & Compounds & Reference \\
\hline $\begin{array}{l}\text { H. perforatum } \\
\text { aerial parts }\end{array}$ & $\begin{array}{l}\text { Fatty oils: medium-chain } \\
\text { triglycerides, Arachis oil refined, } \\
\text { soybean oil refined, almond oil, } \\
\text { sunflower oil refined, sunflower oil } \\
\text { refined, maize germ oil refined, } \\
\text { macadamia nut oil refined, olive oil, } \\
\text { sesame oil refined, Simmondsia } \\
\text { chinensis seed oil }\end{array}$ & $\begin{array}{l}\text { Quercetin, kaempferol, biapigenin, } \\
\text { hyperforin, adhyperforin }\end{array}$ & [63] \\
\hline $\begin{array}{l}\text { H. perforatum } \\
\text { aerial parts }\end{array}$ & $\begin{array}{l}\text { Olive oil, followed by DMSO } \\
\text { (dimethyl sulfoxide) extraction }\end{array}$ & $\begin{array}{l}\text { Quercetin, 4-hydroxyben- zoic acid, } \\
\text { ferulic acid, kaempferol, p-coumaric } \\
\text { acid, pinoresinol, protocate- chuic acid, } \\
\text { vanillic acid, 2-hydroxycinnamic acid, } \\
\text { 3.4-dihydroxyphenylacetic acid, } \\
\text { 3-hydroxybenzoic acid, apigenin, } \\
\text { luteolin, pyrocatechol, rosmarinic acid, } \\
\text { sinapic acid, syringic acid and vanilin }\end{array}$ & {$[64,65]$} \\
\hline $\begin{array}{l}\text { Hypericum spp. } \\
\text { aerial parts }\end{array}$ & Chloroform: methanol 2:1 & Fatty acids & {$[66]$} \\
\hline $\begin{array}{l}\text { H. perforatum } \\
\text { aerial parts }\end{array}$ & Water & Essential oils & [67] \\
\hline $\begin{array}{l}\text { Hypericum spp. } \\
\text { aerial parts }\end{array}$ & Dichloromethane: methanol 1:1 & $\begin{array}{l}\text { Phenolic acids, flavonols, biflavones, } \\
\text { naphthodianthrones } \\
\text { and phloroglucinols }\end{array}$ & [68] \\
\hline
\end{tabular}

It can be clearly seen that polyphenols can be extracted in polar solvents, especially in hydroalcoholic ethanol or methanol, or even in hydroglycerolic medium, while hydrophobic compounds or may be extracted by changing the polarity of the extraction solvent, which may be obtained by increasing the alcoholic or glycerolic concentrations [57].

The most frequently used solvents are ethanol and methanol, either at $100 \%$ or in different dilutions, significantly improving the extraction of most of the types of compounds. Ethanol of different concentrations (decreasing concentrations-100\%,80\%,70\% and $60 \%$ ) appears to be the most efficient way to extract all types of compounds that may be found in the chemical composition of Hypericum species: anthraquinone derivatives (hypericin, pseudohypericin), prenylated phloroglucinol (hyperforin), chlorogenic acids (chlorogenic and neochlorogenic acid) and flavonoids (amentoflavone, catechins, quercetin, quercitrin, isoquercetin, hyperoside and rutin) [69].

Some extraction methods do not use solvents and are based on microwave technology for the extraction of essential oils [67]. The vegetal material consisted, in most of the cases, of the dried aerial parts of the species, which were extracted with the above-mentioned solvents and then completely evaporated until becoming a powdered extract $[3,11,16,18,33,56,70,71]$. Nevertheless, some studies use in vitro cultivated species [32,52,55,62,71,72].

\subsubsection{Extraction Methods}

The large variety of the species belonging to the Hypericum genus and the wide range of secondary metabolites that can be found in their composition indicate the fact that it is difficult to perform an adequate assessment just by using a single extraction solvent or a single extraction method [4]. This is the main reason for which numerous variants of extraction methods, using different extraction solvents and extraction parameters, have been developed over the years, allowing therefore to improve and increase the extraction rates and yields of the compounds that can be found in the composition of vegetal materials belonging to the Hypericum genus. The choice of the extraction method clearly depends on the compounds and their properties (e.g., polarity, solubility), and is performed following the further aims of the concerned study: either testing the biological activity of a species of the genus, establishing connections between species of the genus or testing the influence of different environmental parameters on the chemical composition and biological properties of the species of the genus. 
Room-Temperature Extraction Techniques

\section{- Room-temperature stirring}

A simple cold stirring with solvents at room temperature may represent an extraction technique for different classes of compounds $[27,29,30,34,39,55,57,60,61,66,70]$. One of the most important conditions in this technique is to avoid light exposure, which may degrade some secondary metabolites which are photosensitive [32,34]. In some methods, extracts were evaporated to dryness under reduced pressure [48,70], especially if n-hexane was used as extraction solvent $[60,61]$, but they can also be directly subjected to analysis after centrifugation [27]. Other techniques, especially those that concern the isolation of special classes of compounds, such as hyperzewalsins [23], polycyclic polyprenylated acylphloroglucinols [25] and hyperforatins [24], involve partitioning between different solvents (e.g., $\mathrm{CH}_{2} \mathrm{Cl}_{2}$, ethyl acetate, $\mathrm{n}$-butanol, petroleum ether and acetone) and using different supports for separation (e.g., Sephadex LH-20, Pharmacia Biotech AB, Uppsala, Sweden) $[23,25]$. For the extraction of fatty acids, the chloroformic layer in the chloroformmethanol mixture was recovered, and solvent was removed in order to obtain methyl esters of fatty acids [66]. Water extracts for the analysis of different flavonoids, hypericin and pseudohypericin, were filtered and centrifuged [55], while a mixture of water-glycerol improved the extraction of polyphenols [57].

\section{- Maceration}

The most frequently found method of extraction is maceration, performed with different solvents $[10,11,26,28,31,38,43,51,53,56,58]$. In most of the cases, obtained macerates were evaporated to dryness $[11,26,28,31,51,53,56,58]$, lyophilized $[14,28]$ or centrifuged [38] before being subjected to analysis, or they were directly injected into the HPLC columns [10,43]. For particular methods, olive oil was used for extraction and DMSO was subsequently added [64]. Maceration with other types of oils may be used for extraction of flavonoids or other polyphenols [63].

Percolation may be used as an alternative extraction method, after maceration, using methanol for the extraction of a special class of compounds, polycyclic polyprenylated acylphloroglucinols (hyperfols) [50]. Similarly, after maceration in ethanol and fractionation by silica gel column chromatography in an n-hexane-Et $t_{2} \mathrm{O}$ gradient, prenylated $\beta$-diketones were obtained [35]. In some methods, in order to separate polyphenols according to their polarity, after maceration with methanol and evaporation to dryness, dry extracts were further dissolved in water and partitioned between n-hexane, dichloromethane, ethyl acetate and n-butanol [16].

\section{Heat Extraction Techniques}

\section{- Classical heating}

The Soxhlet extraction method using heat may be used both for removing chlorophyll content, using chloroform, but also for extraction of different compounds, such as flavonoids [10,19,33,49], polyphenols and hypericins [33,46,65]. In order to obtain dry extracts, solvent was evaporated to dryness $[33,49]$. At the same time, classical heating may be used for the extraction of polysaccharides [21]. Decoctions may represent good extraction alternatives for the extraction of polyphenols and flavonoids [51].

\section{- Ultrasonication}

Besides maceration, ultrasonication is one of the most frequently used extraction techniques for different classes of compounds $[2,4,5,18,22,32,45,47,51-53,59,68]$. Most of the studies use temperatures of $40{ }^{\circ} \mathrm{C}[5,22,45,47,51,59,68]$ and $30 \mathrm{~min}$ as an extraction time $[2,4,5,18,32,45,51-53,68]$, while the solvent-to-material ratio is maintained at $1: 10$. It may be followed by centrifugation $[2,4,18,51,52]$, by drying under reduced pressure $[22,32,53,59,68]$ or directly by the analysis after membrane filtration $[5,44,45,47]$, before being subjected to chromatography. In some cases, ultrasonication was performed after the vegetal material was macerated and evaporated under nitrogen [15]. 
Hydrodistillation

For the Hypericum spp. aerial parts, hydrodistillation is used for the obtention of essential oils $[19,48,67,73-76]$, which may be diluted in n-hexane before being subjected to analysis [54,73]. This extraction method concerns the use of a Clevenger-type apparatus, and the method is described in the European Pharmacopoeia, using water as extraction solvent [67]. Dehydration of essential oils was performed using dry sodium sulfate $[67,74-76]$.

\section{Microwave Extraction}

Solvent-free methods concerning microwave-assisted extractions do not use solvents $[20,41]$. In fact, the vegetal material is moistened by spraying water on it to reach a fixed moisture content. The microwave heating of the water in the vegetal material releases the molecules in the essential oil, driven by the obtained vapors. Afterwards, the cooling system inside the extraction apparatus allows the continuous condensation of the distillate. The isolated essential oils are then dried with anhydrous sodium sulphate. The extraction rate of this method is accelerated in these types of methods by the fast increase in the temperature of extraction. When compared to hydrodistillation, which is also used for the extraction of essential oils, it seems that there is a difference in the extraction yield of different compounds, which may be due to the heat transfer and mass transfer, which occur on opposite sides, while for the microwave they occur in the same direction, facilitating diffusion [67]. Parameters used for microwave-assisted extraction of hypericin consisted of soaking the vegetal material for $30 \mathrm{~min}$ at $60^{\circ} \mathrm{C}$ and extracting at $50{ }^{\circ} \mathrm{C}$ for $9 \mathrm{~min}$ [41], while for obtention of crude polysaccharide extracts from $H$. perforatum, the vegetal material was extracted for $60-180 \mathrm{~min}$ at $50-90{ }^{\circ} \mathrm{C}$, before being thrice refluxed with $80 \%$ ethanol in water at $60{ }^{\circ} \mathrm{C}$ for $8 \mathrm{~h}[20]$.

\section{Supercritical $\mathrm{CO}_{2}$ Extraction}

This method is an extraction technique that allows one to obtain high-quality vegetal products that may be used in the pharmaceutical, cosmetics or food industry, using environmentally friendly extraction conditions. It is especially useful for the analysis of essential oils, using high temperatures and pressures, and it is reported that the efficiency of essential oil extraction with liquid or supercritical $\mathrm{CO}_{2}$ is higher than hydrodistillation [17]. The cosolvent used for extraction may be $10 \%$ aqueous ethanol, and extracts may subsequently be reduced using gaseous nitrogen under reduced pressure [77].

\section{Preparative Chromatography for Extracts}

Preparative chromatography is often used to isolate different fractions from the crude extracts, followed by analytical separations and identification of compounds through highperformance liquid chromatography. Crude extracts from $H$. foliosum, H. androsaemum and $H$. perforatum originated from Portugal were processed through low-pressure liquid chromatography using a reversed-phase stationary phase, with particles sizes between 43 to $60 \mu \mathrm{m}$. Moreover, separations of fractions or purification of some compounds from Hypericum species extracts can be achieved using permeation gel column chromatography and polar mobile phases such as mixtures between methanol and water [36].

New macroporous-resin column techniques coupled to preparative liquid chromatography are used for hypericin isolation from $H$. perforatum extracts. Five different macroporous resins were tested and evaluated, and the most suitable one turned out to be the Xad16 N weak-polarity microporous resin. This method, coupled further on with preparative liquid chromatography, using, as eluting solvents, acetonitrile and water, under gradient elution mode was able to improve the recovery rates of hypericin by up to $98 \%$ [78]. 


\subsection{Analysis of Compounds}

Quantitative analysis of compounds that can be found in the composition of different Hypericum species is most frequently performed by liquid chromatography, while qualitative approaches can be very different [4].

Hypericum species represent a valuable source of biologically active compounds that can positively favor the evolution of different types of pathologies. The chemical composition of multiple species belonging to the Hypericum genus, including the well-known $H$. perforatum, is often determined using different types of analytical methods, depending on the category or phytochemical class to which the secondary metabolites belong. Analysis of the chemical composition aims to better understand plant composition in terms of secondary metabolites, the influence of different environmental factors, variations of the chemical compounds between species and subspecies, antioxidant capacity, antibacterial, virucide, antifungal or other biological activities, and to better understand the pharmacological mechanisms for which Hypericum spp. secondary metabolites are responsible.

Hypericum species are widely investigated in terms of secondary metabolites and chemical composition, using different analytical techniques depending on the chemical classes of compounds. The main analytical techniques used for the qualitative and quantitative analysis of the chemical composition in all the articles that were taken into consideration for this review belong to the following categories:

- Separation methods and hyphenated separation methods: liquid chromatographic methods-high-performance liquid chromatography and ultra-high-pressure liquid chromatography (HPLC and UHPLC), liquid chromatography coupled to (tandem) mass spectrometry (LC-MS, LC-MS/MS), thin-layer chromatography and high-performance thin-layer chromatography (TLC and HPTLC), gas chromatographic methods-gas chromatography (GC), gas chromatography coupled to (tandem) mass spectrometry (GC-MS, GC-MS/MS); electrophoretic methods-capillary zone electrophoresis (CZE);

- Optical molecular spectroscopy-based methods and optical atomic spectroscopy-based methods: molecular electronic ultraviolet-visible spectroscopy (UV-VIS); near-infrared and medium-infrared molecular vibrational spectroscopy - near-infrared (NIR) and Fourier-transform infrared spectroscopy (FT-IR); atomic absorption spectroscopy (AAS); atomic emission spectroscopy (AES); inductively coupled plasma atomic emission spectroscopy (ICP-OES).

Finally, powerful analytical techniques for chemical structural elucidation such as nuclear magnetic resonance (NMR) are used in order to identify new compounds in Hypericum genus species.

Parameters and characteristics such as chemical structure, volatility of compounds, solubility, polarity, hydrophobicity, ionizable functional groups, $\mathrm{pKa} / \mathrm{pKb}$ values, and number of chromophores, have a high impact on the types of the employed analytical methods. Lipophilic naphthodianthrones derivatives and phloroglucinols derivatives can be easily separated and retained using reversed-phase stationary phase while employing HPLC or UHPLC separation methods. Flavonoids are usually analyzed using separation methods (HPLC or UHPLC) next to phenolic acids. Due to ionizable groups, phenolic acids can also be analyzed using capillary electrophoresis. UV-VIS is often used to determine the total amount of phenolic acids and total content of flavonoids using specific reagents. Hypericum species also contain volatile compounds such as terpenes (monoterpenes, sesquiterpenes, terpenoids) and fatty acids. The elective analysis method for the volatile compounds of Hypericum species is GC or GC-MS.

The objective of this chapter is to extensively and explicitly present the main analytical methods, parameters and a performance evaluation for the applied and developed techniques used, in order to analyze, identify, quantify or elucidate the chemical structure of the specific compounds found in the species of the Hypericum genus. 


\subsubsection{Separation Methods and Hyphenated Separation Methods}

Separation methods represent by far the largest category of analytical techniques used for the analysis of different chemical compounds in the composition of Hypericum species or for the analysis of different types extracts that are obtained from their vegetal material. Separation methods are used to solve particular applications in different contexts that involve Hypericum species, such as general chemical profiling; fingerprinting and species differentiation; quality assessment and quality control; phytochemical characterization of uninvestigated species from different parts of the world; assessment of newly developed extractive methods and procedures; the study of different exterior factors such as physical, chemical or biological factors that may impact the chemical composition; genetic variations; determination of the elicitation effect of different substances; in vivo and in vitro antioxidant, enzymatic and pharmacological activity; antibacterial and antifungal activity. For this plethora of applications, accurate separation methods have been developed in order to identify, quantify or to elucidate chemical structures of newly detected compounds.

An extensive literature review was performed regarding separation methods for different kinds of applications involving the Hypericum genus, with a special focus on chromatographic methods. Data comprising 76 chromatographic methods (HPLC, UHPLC, LC-MS(/MS), GC and GC-MS(/MS) are summarized and displayed in three different supplementary data tables (Tables S1-S3). Summarized data tables cover information regarding the studied species, plant part, phytochemical class of compounds, specific compounds that were investigated, type of stationary phases and stationary phase characteristics, employed mobile phases, run time and type of detection. Data presented in Tables S1-S3 offer an overview regarding the possibility of analyzing different types of compounds. A general overview will be discussed further on, based on the type of the separation technique.

\section{High-Pressure and Ultra-High-Pressure Liquid Chromatography}

HPLC and UHPLC are the preferred techniques used to determine chemical composition of the Hypericum extracts. Multiple analytical methods have been developed depending on the phytochemical class of compounds or on the envisaged applications.

Naphthodianthrones are specific compounds for Hypericum species and are usually investigated and quantified in all types of Hypericum genus species. The main naphthodianthrones representatives are hypericin, pseudohypericin, protohypericin and protopseudohypericin. Precursors of naphthodianthrones are the anthraquinones emodin and skyrin and their derivatives-oxyskyrin, iridoskyrin, rubroskyrin [32]. Multiple studies have revealed that in order to separate and analyze naphthodianthrones, reversed-phase separation mode can be employed [2,46,52,71,79]. C18 (octadecylsilyl) is the most commonly used stationary phase $[26,32,37,51,80]$. However, other RP (reversed phase) chemistries with lower hydrophobicity are reported for hypericin analysis, such as C8 (octyl) [81]. Fully porous stationary phase can be successfully used for the analysis of naphthodianthrones, and monolith columns can allow for rapid analysis and lower retention of pseudohypericin and hypericin [20].

Mobile phases consisting of different mixtures between an aqueous component and an organic modifier such as acetonitrile and methanol are often used. The aqueous component is usually acidified with formic acid, trifluoroacetic acid, or phosphoric acid [41,44,46,62,69,71], or buffered with ammonium acetate $[43,82]$. Ethyl acetate can also be used in the composition of the mobile phase together with methanol and sodium dihydrogen phosphate (adjusted to $\mathrm{pH}=2$ with phosphoric acid) $[45,83]$. Retention of naphthodianthrones is improved significantly while using acidic mobile phase additives or buffer solutions that are able to create an acidic $\mathrm{pH}$ value of around $2.0[41,43,44,46,82]$. In order to detect naphthodianthrones such as hypericin or related compounds, UV-VIS detectors or photo diode array detectors/diode array detectors (PDA/DAD) are usually coupled at the end of the chromatographic column while scanning at a specific wavelength for this compounds at $590 \mathrm{~nm}$ or closer, such as $520 \mathrm{~nm}$ and $560 \mathrm{~nm}[5,34,48,80,84]$. 
Hypericum genus species are also rich in phloroglucinols and their derivatives. The main classes of phloroglucinols that are investigated using HPLC and UHPLC techniques are the acylphloroglucinols, dimeric acylphloroglucinols and polycyclic polyprenylated acylphloroglucinols $[85,86]$. Phloroglucinols derivatives are frequently analyzed using RP stationary phases such as C18 [2,52,59,62,63] and phenyl stationary phase [36]. The mobile phases used for RP separations of phloroglucinols derivatives are based on mixtures that contain an aqueous component acidified with formic acid, trifluoroacetic acid or phosphoric acid, and an organic modifier such as acetonitrile or methanol $[5,37,44,45,58,87]$. Sometimes, the aqueous component can be a buffer such as acetic acid/ammonium acetate buffer [26]. PDA and DAD detectors were primarily used for the detection of the phloroglucinols in UV spectrum domains at different wavelengths, depending on the compounds. Compounds were commonly detected at 270,290 or $370 \mathrm{~nm}[5,34,48,61]$. Even though the selectivity of the method can be changed or improved for some phloroglucinols derivatives while using phenyl stationary phase [36], the preferred stationary phase remains $\mathrm{C} 18$ with acidic $\mathrm{pH}$ values of mobile phases.

Analysis of phenolic acids of the Hypericum species extracts by HPLC is made possible by using different analytical approaches that employ RP-C18 stationary phases coupled to UV-VIS or DAD detectors [20,39,79,80,88-91]. Mobile phases used for the analysis of phenolic acids consist mainly of acidified aqueous solvents mixed with acetonitrile or methanol. Phenolic acids are small molecules with phenol and carboxyl functional groups. Phenolic groups can induce an increase in polarity, while the dissociation of carboxyl groups at a high $\mathrm{pH}$ value can decrease the affinity for a hydrophobic stationary phase. Thus, mobile phases are usually acidified in order to induce the formation of the undissociated form while increasing hydrophobicity, and finally the retention of a RP hydrophobic stationary phase. Moreover, simultaneous analysis of phenolic acid compounds next to naphthodianthrones and phloroglucinol derivatives is feasible $[36,39,44,48,69,84]$. Flavonoids and flavonoids derivatives, either as aglycones or glycosylated flavonoids, are usually determined and separated through HPLC by using mainly RP mechanisms $[39,51,79,84,88]$.

HPLC or UHPLC methods are also able to separate other compounds that are usually found in much lower concentrations, such as: tocopherols [63,66]; xanthones [54,72,92,93]; skyrin derivatives-iridoskyrin, rubroskyrin, luteoskyrin, oxysckyrin [32]; benzophenones and benzopyrans [58]; bisanthrones [32]; cyclitos [51] and even amino acids. All these compounds are usually detected using DAD and UV-VIS detectors. However, fluorescence detectors were reported for the analysis of free amino acids, after a previous derivatization with o-phthalaldehyde and 9-fluorenylmethyl chloroformate [90].

C18 is the elective stationary phase due to the versatility of this phase in accordance with the studied compounds. The most used mobile phase mixtures consist mainly of water, methanol and acetonitrile. However, selectivity, retention and resolution can be further improved by employing different particle sizes; particle porosity; types of particles (fully porous, monolytic, fused-core particles), or by changing different chromatographic parameters such as elution mode, gradient types and gradient slopes.

Sometimes TLC techniques or HPTLC are used for quality control purposes or phytochemical screening for uninvestigated species, and may forego HPLC and UHPLC analysis $[26,94]$.

\section{Liquid Chromatography Coupled to Mass Spectrometry}

The improved specificity, selectivity and sensibility of LC-MS and/or LC-MS/MS techniques represent an asset when these techniques are used for phytochemical profiling of particularly unstudied Hypericum species. Since a significant class of phytochemical compounds can be separated using RP-separation mechanisms and polar solvents as mobile phases, the coupling with mass spectral methods is easy and feasible. Different mass analyzers are usually employed for the targeted and untargeted analysis of Hypericum species, such as ion traps $[18,19,27]$, single quadrupoles [38,57,59], orbitraps [32,68] and even hybrid mass analyzers such as triple quadrupoles (QQQ) $[40,51,80,90]$, quadrupole-ion 
traps (Qtraps) [62] and quadrupole time of flight QTOF [26,42,48]. Electrospray ionization sources (ESI) were used both in negative ionization mode (ESI-) and positive ionization mode (ESI+), depending on the targeted compounds. For the untargeted analysis, phytochemical profiling and fingerprinting, usually both ionization modes were used to cover as many compounds as possible $[18,20,48]$. The literature records multiple studies where targeted analysis was performed using particular MRM (multiple reaction monitoring) scan modes and triple quadrupoles were used as mass analyzers. Nevertheless, untargeted analysis applications were solved using scan and full-scan modes with the help of QTOFs orbitraps and Qtraps [51,80,90,95].

The phytochemical composition in terms of secondary metabolites for many species of the Hypericum genus, including $H$. perforatum from different parts of the world, were determined through LC-MS and LC-MS/MS. H. perforatum; H. maculatum; H. Hirsutum and $H$. tetrapterum extracts were screened for bioactive compounds, and antioxidant capacity was eventually determined based on the phytochemical composition. Three Hypericum species from Sardinia (H. scruglii, H. hircinum, H. perforatum) were screened with the help of an LC-ESI negative-QQQ, and the $\alpha$-glucosidase inhibitory activity was determined. Phytochemical investigation using LC-MS techniques for species such as $\mathrm{H}$. cardonae, H. myricariifolium, $H$. laricifolium, H. humboldtianum, H. garciae, H. carinosum and H. cuatrecasii from the remote Columbian Andes mountains was focused on flavonols, flavan-3-ols, stilbenoids, coumarins, cinnamic acids and flavones [40]. However, LC-MS and LC-MS/MS made possible the analysis of different Hypericum species from other particular parts of the world such as the Northern Republic of Macedonia, Canary Islands, Greece or the People's Republic of China [18,19,42,48].

Besides phytochemical profiling, LC-MS/MS has been involved in other special applications where the chemical composition of the Hypericum genus was needed, for example, the evaluation of acylphloroglucinols composition (uliginosin A, isouliginosin B, isohyperbrasilol, uliginosin B, hyperbrasilol B) on the antichemotactic activity of lipophilic extracts from Peruvian Hypericum species [59]. Other studies evaluate the influence of some external factors on the composition of Hypericum species. In order to increase the number of naphthodianthrones synthesized by $\mathrm{H}$. perforatum, a study reports and confirms that nanoperlites and $\mathrm{MnO}_{2}$ / perlite-NCs have a positive effect in terms of hypericin and pseudohypericin content [55]. Other external factors have been studied, such as the presence of lanthanum and cadmium. These two compounds, especially lanthanum, proved to produce modifications in the metabolic profile of H. perforatum. This conclusion was possible thanks to the MRM-targeted analysis while investigating different classes of compounds such as phenolic acids, flavonols, epicatechin, procyanidins and naphthodianthrones [96]. By using an LC-DAD-ESI ion trap system, and based on mass spectral data and UV-VIS, a comparison between the species $H$. perforatum and $\mathrm{H}$. maculatum was performed based on phenolic acids, naphthodianthrones and flavonoids content, revealing distinct betweenyear and between-species diversity. The study also revealed that $\mathrm{H}$. maculatum contains trace amounts of rutin, with a tendency to accumulate more phenolic compounds [27]. Applications regarding plant authenticity for Hypericum species are also of high interest. An original research study where compounds from different classes were analyzed through LC-MS full-scan mode proved that the ratio of hyperforin and furophyperforin allows the ranking the raw materials of $H$. perforatum depending on the place of growth, and the ratio between the rutin content and hyperforin content proved to be a good marker for the quality of the vegetal material belonging to H. perforatum [20]. Eventually, even antityrosinase activity and antiaging potential of three Hypericum species (H. perforatum; H. calycinum; $H$. confertum) was investigated through targeted MRM analysis by LC-ESI-QQQ [14].

Gas Chromatography and Gas Chromatography Coupled to Mass Spectrometry for Volatile Compounds

Even though Hypericum genus species are not renowned for volatile compounds, GC and GC-MS is an ideal tool for the analysis of some compounds such as fatty acids 
or terpene derivatives from essential oils. These types of compounds analyzed from Hypericum species extracts are mainly separated and analyzed using film-coated capillary columns $[21,47,54,67]$. In order to improve retention and separation, derivatization was used for some types of compounds, either on column or before the injection [54,63]. Helium and nitrogen were the most encountered gas carriers used for the analysis of many of the compounds $[66,76]$. Due to the high content of carbon atoms of fatty acids and terpenes, a flame ionization detector can be used as the elective detection method [63]. However, mass spectrometry using electron impact ionization can provide better insight on the chemical composition, and can be of real help for fingerprinting, profiling or for special applications in which an external factor, e.g., altitude was studied [47], or when biochemical elucidation mechanisms are envisaged [54]. Identification of compounds can be performed using reference standards, however, for certain reported methods, when multiple compounds are analyzed, Kovats Index and other linear retention indices can be used [47,67,73]. Moreover, when MS detection is used, then mass spectra for the obtained compounds can be compared to reference spectra from different libraries [19,73,75].

Research based on the chemical content of Hypericum genus extracts revealed different classes of volatile compounds. H. perforatum, H. perfoliatum, H. tomentosum, H. ericoides-four Tunisian Hypericum species-were investigated for their content in fatty acids and tocopherols [66]. Fatty acids were also analyzed as methyl esters obtained through on-column trimethylsulfonium hydroxide derivatization [63]. It was demonstrated that H. perforatum can contain also mono- and sesqui-terpenes [55] and oxygenated mono- and sesquiterpenes for $H$. perforatum species coming from Iran [76]. New, interesting compounds such as prenylated $\beta$-diketones (2,6,9-trimethyl-8-decene-3,5-dione and 3,7,10-trimethyl9-undecene-4,6-dione) were identified and confirmed using GC-MS and electron-impact ionization mode [35].

Unexplored species (e.g., H. perforatum ssp. veronense; H. perfoliatum; H. empetrifolium ssp. empetrifolium; H. triquetrifolium from Greece) were analyzed using GC and GC-MS for their volatile compounds content $[17,19,69,73,74,76]$, and 113 different compounds were identified [48]. H. rochelii and H. umbellatum were investigated through GC-FID and GC-MS, revealing a significant number of volatile compounds, out of which the terpene class is the best represented [74].

\section{Capillary Electrophoresis}

Capillary zone electrophoresis techniques represent a greener alternative to HPLC or UHPLC, due to its minimum consumption of solvents, requiring a small amount of sample to be injected into the capillary. Capillary electrophoresis makes no exception from the separative methods used for chemical fingerprinting. Phenolic acids and flavonoid glycosides were able to be identified using a fused silica capillary and a $50 \mathrm{mM}$ sodium tetraborate $\mathrm{pH}=9.1$ separation buffer [97].

Capillary electrophoresis (CE) was found to be insufficiently sensitive for naphthodianthrones and phloroglucinol derivatives using a separation buffer with $\mathrm{pH}=3.0$, and was overall less reproducible [87]. Lipophilic compounds such as hypericin and hyperforin were able to be analyzed using nonaqueous medium containing methanol, dimethylsulfoxide N-methyl formamide (3:2:1) as solvent, and $50 \mathrm{mM}$ ammonium acetate, $150 \mathrm{mM}$ sodium acetate and $0.02 \%(w / v)$ of cationic polymer hexadimethrine bromide. Flavanoids and chlorogenic acid were analyzed using micellar electrokinetic electrophoresis, using sodium dodecyl sulphate as a surfactant. The results showed that while the methods for the analysis of flavonoids were considered to be suitable, quantification by HPLC and CE did not reveal significant differences in terms of analytical performances [4].

\subsubsection{Molecular and Atomic Optical Spectroscopic Methods}

Optical spectral methods, such as UV-VIS molecular spectroscopy, vibrational IR spectroscopy or ICP-OES, are usually used for screening purposes, and usually assist the specific applications for Hypericum extracts such as enzymatic activity, antioxidant activity 
and correlations with total amount of flavonoids, phenols or even structural elucidation for unidentified compounds when FT-IR is employed.

UV-VIS molecular spectroscopy is an affordable and inexpensive technique, often used for quality assessment of medicinal plants and dietary supplements including those that contain Hypericum plant parts.

Naphthodianthrones, which can be considered as anthraquinone derivatives, are specific compounds biosynthesized in almost all species belonging to Hypericum genus $[6,85,98]$. Hypericin is the most encountered naphthodianthrone, alongside pseudohypericin, protohypericin, protopseudohypericin. In order to evaluate extraction efficiency of these compounds, or to assess the quality of plants and dietary supplements containing Hypericum species, total hypericin content is quantitatively evaluated using UV-VIS spectrometry, determining the absorbance values of processed extracts at a specific wavelength of $590 \mathrm{~nm}$. The UV-VIS method for hypericin dosage of $H$. perforatum is also officialized by the current version (10.7) of the European pharmacopoeia [8]. This general method is used in order to assess and improve extraction procedures of biologically active compounds from H. perforatum plants [29], determine the authenticity and quality of medicinal plants [94] or for characterization of macerates with different fatty oils obtained based on $H$. perforatum plants parts [63]. By using the UV-VIS method, the total content in hypericin can be calculated based on the specific absorbance or based on calibration curves plotted using reference standards [8].

Phenolic compounds represent a major source of antioxidants in the Hypericum genus, and are usually investigated and determined as total phenolic content, eventually correlating with the antioxidant activity [99]. Usually, total phenolic content is assessed based on the well-known Folin-Ciocâlteu reagent and expressed as gallic acid equivalents while reading the absorbance of samples and standard solutions at $760 \mathrm{~nm}$. Assessment of total phenolic content of Hypericum species is performed in different contexts, such as temperature influence and temperature-dependent growth parameters of Hypericum species [81] or other chemical dependent factors [84], phytochemical profile of particular Sardinian Hypericum species, such as H. scruglii and H. hircinum [51], study of Canary Islands $H$. reflexum, $H$. canariense and $H$. grandifolium, evaluation of the chemoprotective effect of $H$. perforatum on rat oral squamous cell carcinoma [33], novel and improved extraction procedures based on microwave extraction [67], usage of special solvents such as glycerol [57], or by successive grinding and sieving [38]. Nevertheless, this analytical approach is often used for screening of total phenolic content for uninvestigated species belonging to Hypericum genus, such as $H$. calycinum, $H$. confertum, and H. perforatum [11] or $H$. androsaemum, $H$. ericoides, $H$. $x$ moserianum and H. olympicum [1].

UV-VIS spectrometry can be successfully used to determine the total flavonoid content. Usually, total flavonoid content is determined as pyrocatechol or quercetin equivalents based on calibration curves. Total flavonoid content of Hypericum species was evaluated, especially for uninvestigated species [16] or in order to assess the quality of the plant products. External factors were researched in order to determine their influence over the secondary metabolites $[81,84]$ or to determine the in vitro biological activities of Hypericum species extracts [11]. In order to assess the chemical composition of Hypericum species, UV-VIS spectrometry is also used to determine the total amount of anthocyanins based on molar extinction coefficient $\left(25,956 \mathrm{M}^{-1} \mathrm{~cm}^{-1}\right.$ using the molecular weight of $\left.449 \mathrm{~g} \mathrm{~mol}^{-1}\right)$. Condensed tannins most often are determined in catechin equivalents [84].

Vibrational spectroscopic methods such as medium-infrared Fourier-transformation infrared spectroscopy and near-infrared spectroscopy represent powerful analytical techniques used for structural elucidation using FT-IR, or for quantitative analysis using NIR accordingly. FT-IR spectrometry was used in order to characterize and investigate functional groups of crude polysaccharides in H. perforatum extracts obtained after design-space surface methodology optimization, and they were analyzed further by FT-IR using KBr pellets and one milligram of extract [21]. Moreover, FT-IR, using an attenuated total reflectance approach, was used for metabolite profiling and species discrimination (between H. annulatul, 
H. calycinum, H. hirsutum, H. hookerianum, H. humifusum, H. maculatum, H. olympicum and H. pseudohenryi) [69]. Crude and filtrated extracts in a study investigating the impact of the filtration process on bioactive extracts incorporated into carbohydrate-based hydrogels were directly investigated and characterized using FT-IR and KBr pelleting [56]. NIR techniques turned out to be of great value for the quantification of specific compounds such as hypericin and hyperforin from the H. perforatum extracts, with good determination coefficients $\left(R^{2}>0.99\right.$ for hypericin and $\left.R^{2}>0.98\right)$ for the concentrations of the investigated compounds relative to a reference liquid chromatographic method [87].

As a complementary tool for Hypericum genus and H. perforatum analysis techniques, ICP-OES was successfully used for elemental analysis and fingerprinting of $H$. perforatum products such as plants, dry herbs, tablets and capsules. Vegetal products, capsules contents and tablet powders were dried and digested with highly pure nitric acid prior to ICP-OES analysis. The developed methods were able to investigate 25 different elements, while revealing through principal component analysis seven key elements: $\mathrm{Ba}, \mathrm{Ca}, \mathrm{Cd}, \mathrm{Mg}, \mathrm{Mo}$, $\mathrm{Ni}$, Y. The major constituents of $\mathrm{H}$. perforatum were revealed to be $\mathrm{Ca}, \mathrm{Mg}, \mathrm{Al}, \mathrm{Fe}, \mathrm{Mn}, \mathrm{Sr}$, and $\mathrm{Zn}[100]$.

\subsubsection{Spectral Methods for Structural Elucidation-Nuclear Magnetic Resonance}

Nuclear magnetic resonance is an analytical technique that is used especially for chemical structure elucidation when Hypericum species applications are investigated. Different NMR techniques are reported in the literature for the analysis of new compounds of the Hypericum genus using ${ }^{1} \mathrm{H}-\mathrm{NMR},{ }^{13} \mathrm{C}-\mathrm{NMR}$ and even ${ }^{2} \mathrm{D}-\mathrm{NMR}$.

Chemical structure of new compounds such as $( \pm)$-hyperzewalsins A-D, representing the first nor-monocyclic, polyprenylated acylphloroglucinols bearing carbon chain constitutions based on diverse highly degraded phloroglucinols, were detected using both ${ }^{1} \mathrm{H}-\mathrm{NMR}(600 \mathrm{MHz})$ and ${ }^{13} \mathrm{C}-\mathrm{NMR}(150 \mathrm{MHz})$, from H. przewalskii Maxim. (Hypericaceae)isolated fractions [23]. NMR represented an important tool when phytochemical profile of the $H$. scruglii, $H$. hircinum and $H$. perforatum was determined. ${ }^{1} \mathrm{H}-\mathrm{NMR}$ revealed that the most abundant secondary metabolites for H. Hircinium were shikimic acid, chlorogenic acid, quercetin and quercetin-7-glucoside. The same components were also identified in $H$. perforatum, which proved to contain also hyperoside and trigonelline. $H$. scruglii proved to contain, alongside shikimic acid and chlorogenic acid, 3-geranyl1-(2'-methylbutanoyl)-phloroglucinol, 3-geranyl-1-(2'-methylpropanoyl)-phloroglucinol and quercitrin [51]. Hyperformitins A-I (9 compounds), which belong to the polycyclic polyprenylated acylphloroglucinols class, and new isomers such as hyperformitins J-M (four compounds), were identified and described in different fractions obtained based on $H$. perforatum extracts. Absolute chemical configurations for garcinielliptone $\mathrm{L}$ and garcinielliptone $M$ next to garsubellins $\mathrm{D}$ and $\mathrm{C}$ were determined for the first time using NMR [25]. The chemical structures of hyperforatins L-U (10 compounds) belonging to the polycyclic polyprenylated acylphloroglucinols class were determined using NMR and were further studied in order to determine their neuroprotective activity, since it is known that this class of compounds can be important for their antidepressive effects and antineurodegenerative activity [2]. The hyperfols (particularly hyperfols C-H), which form another subclass of polycyclic polyprenylated acylphloroglucinols, were also identified in $H$. perforatum extracts, whereas the chemical structure was elucidated based on ${ }^{1} \mathrm{H}-\mathrm{NMR}$ and ${ }^{13} \mathrm{C}-\mathrm{NMR}$ [50]. Nevertheless, NMR can be used also as a tool for untargeted analysis coupled to principal component analysis in the context of authenticity assessment, adulteration discovery and quality control of different herbal medicinal products derived from the Hypericum genus [94].

Important demands in terms of increased market share and export rates of Hypericum plant-based medicinal products results in the appearance of counterfeit products adulterated with $H$. perforatum cultivars with distinct chemotypes [101,102]. 


\section{Concluding Remarks and Future Perspectives}

The necessity of standardized methods for the quality assessment of Hypericum herbal products has increased over the years, especially as herbal products may be altered due to misidentification or confusions, offering serious safety concerns. As the market share is expected to grow in the upcoming years, it appears important to study the species of the Hypericum genus in different ways, in order to offer significant scientific evidence to support their correct use in the therapy of several pathologies. It might be interesting to observe, in future studies, the evolution on the market of cosmetic products, supplementary foods and nutraceuticals that employ Hypericum extracts in their composition. Nevertheless, high difficulty of data gathering is envisaged due to the lack of harmonized worldwide legislation and regulation. These facts are responsible for the incorrect integration of this products in certain categories of consumer goods for health.

The Hypericum genus contains one of the most extensively studied and widely known species, $H$. perforatum, but also other species that may present similar properties, especially as this genus has numerous representatives and is one of the largest flowering plant genera. A significant number of species have not yet been studied. However, their important pharmaceutical potential remains to be determined and to be compared to the officinal species, starting from the extracts and then continuing with the phytochemical analysis and biological evaluation of their properties, having as a final purpose a significant relevance from the medical, cosmeceutical and nutraceutical points of view. In this regard, the gap for future studies on the genus becomes larger and larger. On the other hand, the mechanisms by which the compounds found in the composition of these species may exert their pharmacological properties are still unclear, which makes the study of the species of the genus even more interesting. All of these points may lead to the development of phytotherapeutical preparations that can be used by patients worldwide for the treatment of a large variety of pathological conditions. Study perspectives of the species of the genus are therefore numerous, and open possibilities for increasing the knowledge on one of the most important vegetal medicinal products.

The Hypericum genus comprises a large variety of secondary metabolites involved in many elucidated or yet undetermined biological mechanisms. Multiple studies have revealed that not only is the species $H$. perforatum of increased interest, but also other species may be of high potential regarding their chemical composition. The procedures used for obtaining extracts vary, from simpler ones up to those assisted by microwaves, ultrasonication or supercritical fluid $\mathrm{CO}_{2}$ extraction. The solvents used for the extraction procedures are almost polar ones; however, organic, less polar solvents or other particular approaches such as the use of olive oil have proved to be suited for further chemical characterization or phytochemical profiling and optimal extraction. Extract analysis using separation methods such as liquid chromatographic methods, often hyphenated with mass spectrometry, cover a high range of phytochemical classes, such as naphthodianthrones, phloroglucinols, phenolic acids or flavonoids. Gas chromatographic methods are generally complementary to LC methods, while some spectral methods such as nuclear magnetic resonance, mass spectrometry and Fourier-transform infrared spectrometry were best suited for the characterization of new compounds. Usually, the newly investigated compounds relate to phloroglucinols phytochemical class and their secondary degrading products. The relevance of all the studies regarding the Hypericum genus are of high biological and medical interest due to its proven antioxidant, pharmacological and antibacterial activities. Finally, the plant diversity of the genus enhances the potential to discover new compounds with biological activity, which means that studies will continue, with direct benefits and improving overall the knowledge regarding the species.

Supplementary Materials: The following supporting information can be downloaded at: https:/ /www. mdpi.com/article/10.3390/separations9010017/s1, Tables S1-S3. References [2,5,10,14,16-21,26,27,30,32, $34-48,51,52,54,55,57-59,61-63,66-69,71-77,79-82,84,87-93,95-97]$ are cited in the Supplementary Materials. 


\begin{abstract}
Author Contributions: Conceptualization, V.I., I.I., G.C. and R.P.; methodology, V.I., I.I., A.-G.C., D.L.M., G.C. and R.P.; investigation, V.I., I.I., G.C. and R.P.; resources, V.I., I.I., A.-G.C., D.L.M., G.C. and R.P.; writing—original draft preparation, V.I., I.I. and R.P.; writing—review and editing, D.L.M., G.C. and R.P.; visualization, I.I., A.-G.C., D.L.M., G.C. and R.P.; supervision, D.L.M., G.C. and R.P. All authors have read and agreed to the published version of the manuscript.
\end{abstract}

Funding: This work was supported by a grant of the Romanian Ministry of Education and Research, CNCS-UEFISCDI, project number PN-III-P1-1.1-PD-2019-0603, within PNCDI III.

Institutional Review Board Statement: Not applicable.

Informed Consent Statement: Not applicable.

Data Availability Statement: Data sharing not applicable.

Conflicts of Interest: The authors declare no conflict of interest. The funders had no role in the design of the study; in the collection, analyses, or interpretation of data; in the writing of the manuscript, or in the decision to publish the results.

\title{
References
}

1. NorMaN, K.B. And then came molecular phylogenetics-Reactions to a monographic study of Hypericum (Hypericaceae). Phytotaxa 2016, 255, 181-198.

2. Bruňáková, K.; Bálintová, M.; Henzelyová, J.; Kolarčik, V.; Kimáková, A.; Petijová, L.; Čellárová, E. Phytochemical profiling of several Hypericum species identified using genetic markers. Phytochemistry 2021, 187, 112742. [CrossRef] [PubMed]

3. de Carvalho Meirelles, G.; Bridi, H.; von Poser, G.L.; Nemitz, M.C. Hypericum species: An analysis on the patent technologies. Fitoterapia 2019, 139, 104363. [CrossRef] [PubMed]

4. Dresler, S.; Kováčik, J.; Strzemski, M.; Sowa, I.; Wójciak-Kosior, M. Methodological aspects of biologically active compounds quantification in the genus Hypericum. J. Pharm. Biomed. Anal. 2018, 155, 82-90. [CrossRef]

5. Cirak, C.; Radusiene, J.; Jakstas, V.; Ivanauskas, L.; Yayla, F.; Seyis, F.; Camas, N. Secondary metabolites of Hypericum species from the Drosanthe and Olympia sections. S. Afr. J. Bot 2016, 104, 82-90. [CrossRef]

6. Zhang, R.; Ji, Y.; Zhang, X.; Kennelly, E.J.; Long, C. Ethnopharmacology of Hypericum species in China: A comprehensive review on ethnobotany, phytochemistry and pharmacology. J. Ethnopharmacol. 2020, 254, 112686. [CrossRef]

7. Săvulescu, T. Flora Republicii Populare Române; Editura Academiei Republicii Populare Române: Bucharest, Romania, 1955; pp. 23-46.

8. Uerpmann-Wittzack, R.; Schmahl, S.; Breuer, M. European Directorate for the Quality of Medicines and HealthCare, Hyperici Herba-ST John's Wort (01/2017 1438); European Pharmacopoeia: Strasbourg, France, 2020; pp. 1631-1633.

9. Committee on Herbal Medicinal Poducts (HMPC). Community Herbal Monograph on Hypericum Perforatum L., Herba (Wellestablished medicinal use). Eur. Med. Agency Eval. Med. Hum. Use 2009, 11, 1-9.

10. Bagdonaite, E.; Mártonfi, P.; Repčák, M.; Labokas, J. Variation in concentrations of major bioactive compounds in Hypericum perforatum L. from Lithuania. Ind. Crops Prod. 2012, 35, 302-308. [CrossRef]

11. Ersoy, E.; Eroglu Ozkan, E.; Boga, M.; Mat, A. Evaluation of in vitro biological activities of three Hypericum species (H. calycinum, H. confertum, and H. perforatum) from Turkey. S. Afr. J. Bot. 2020, 130, 141-147. [CrossRef]

12. Silva, A.R.; Taofiq, O.; Ferreira, I.C.F.R.; Barros, L. Hypericum genus cosmeceutical application-A decade comprehensive review on its multifunctional biological properties. Ind. Crops Prod. 2021, 159, 113053. [CrossRef]

13. Galeotti, N. Hypericum perforatum (St John's wort) beyond depression: A therapeutic perspective for pain conditions. J. Ethnopharmacol. 2017, 200, 136-146. [CrossRef] [PubMed]

14. Ersoy, E.; Eroglu Ozkan, E.; Boga, M.; Yilmaz, M.A.; Mat, A. Anti-aging potential and anti-tyrosinase activity of three Hypericum species with focus on phytochemical composition by LC-MS/MS. Ind Crops Prod. 2019, 141, 1-9. [CrossRef]

15. Nogueira, T.; Medeiros, M.A.; Marcelo-Curto, M.J.; García-Pérez, B.E.; Luna-Herrera, J.; Costa, M.C. Profile of antimicrobial potential of fifteen Hypericum species from Portugal. Ind. Crops Prod. 2013, 47, 126-131. [CrossRef]

16. Saddiqe, Z.; Naeem, I.; Hellio, C.; Patel, A.V.; Abbas, G. Phytochemical profile, antioxidant and antibacterial activity of four Hypericum species from the UK. S. Afr. J. Bot 2020, 133, 45-53. [CrossRef]

17. Ji, Y.-Y.; Yang, J.-Y.; Zhang, R.-F.; Chen, Q.-Y.; Xu, R.; Wei, X.-J.; Chen, X.-H.; Chen, S.-X.; Guo, F.-D.; Kennelly, E.J.; et al. Chemical characterization, neuroprotective, antimicrobial and enzyme inhibitory activities of Hypericum volatile oils. Ind. Crops Prod. 2021, 172, 1-12. [CrossRef]

18. Tusevski, O.; Krstikj, M.; Stanoeva, J.P.; Stefova, M.; Gadzovska Simic, S. Phenolic profile and biological activity of Hypericum perforatum L.: Can roots be considered as a new source of natural compounds? S. Afr. J. Bot. 2018, 117, 301-310. [CrossRef]

19. Zorzetto, C.; Sánchez-Mateo, C.C.; Rabanal, R.M.; Lupidi, G.; Petrelli, D.; Vitali, L.A.; Bramucci, M.; Quassinti, L.; Caprioli, G.; Papa, F.; et al. Phytochemical analysis and in vitro biological activity of three Hypericum species from the Canary Islands (Hypericum reflexum, Hypericum canariense and Hypericum grandifolium). Fitoterapia 2015, 100, 95-109. [CrossRef] 
20. Temerdashev, Z.; Milevskaya, V.; Vinitskaya, E. The method of establishing the authenticity and quality of Hypericum perforatum L. and Salvia officinalis L. MethodsX 2021, 8, 101487. [CrossRef]

21. Heydarian, M.; Jooyandeh, H.; Nasehi, B.; Noshad, M. Characterization of Hypericum perforatum polysaccharides with antioxidant and antimicrobial activities: Optimization based statistical modeling. Int. J. Biol. Macromol. 2017, 104, 287-293. [CrossRef] [PubMed]

22. Sofi, S.H.; Nuraddin, S.M.; Amin, Z.A.; Al-Bustany, H.A.; Nadir, M.Q. Gastroprotective activity of Hypericum perforatum extract in ethanol-induced gastric mucosal injury in Wistar rats: A possible involvement of $\mathrm{H}+/ \mathrm{K}+$ ATPase $\alpha$ inhibition. Heliyon 2020, 6, e05249. [CrossRef] [PubMed]

23. Duan, Y.; Bu, P.; Xie, S.; Guo, Y.; Shi, Z.; Qi, C.; Zhang, Y. ( \pm )-hyperzewalsins A-D, four pairs of nor-monocyclic polyprenylated acylphloroglucinols with immunosuppressive activity from hypericum przewalskii maxim. Phytochemistry 2021, 187, 112779. [CrossRef]

24. Guo, Y.; Zhang, N.; Duan, X.; Cao, Y.; Xue, Y.; Luo, Z.; Zhu, H.; Chen, C.; Wang, J.; Zhang, Y. Hyperforatins L-U: Prenylated acylphloroglucinols with a terminal double bond from Hypericum perforatum L. (St. John's Wort). Phytochemistry 2019, 164, 41-49. [CrossRef] [PubMed]

25. Guo, Y.; Cao, Y.; Qi, C.; Tong, Q.; Chen, C.; Yang, J.; Zhu, H.; Zhang, Y. Polycyclic polyprenylated acylphloroglucinols with immunosuppressive activity from Hypericum perforatum and absolute configurations assignment of previously reported analogues. Bioorganic Chem. 2021, 114, 105144. [CrossRef] [PubMed]

26. Ccana-Ccapatinta, G.V.; Flores, C.S.; Soria, E.J.U.; Pari, J.C.; Sánchez, W.G.; Crockett, S.L.; von Poser, G.L.; Jimenez, C.D.C. Assessing the phytochemical profiles and antidepressant-like activity of four Peruvian Hypericum species using the murine forced swimming test. Phytochem. Lett. 2014, 10, 107-112. [CrossRef]

27. Rusalepp, L.; Raal, A.; Püssa, T.; Mäeorg, U. Comparison of chemical composition of Hypericum perforatum and H. maculatum in Estonia. Biochem. Syst. Ecol. 2017, 73, 41-46. [CrossRef]

28. Altun, M.L.; Yilmaz, B.S.; Orhan, I.E.; Citoglu, G.S. Assessment of cholinesterase and tyrosinase inhibitory and antioxidant effects of Hypericum perforatum L. (St. John's wort). Ind. Crop. Prod. 2013, 43, 87-92. [CrossRef]

29. Koturevic, B.; Adnadjevic, B.; Jovanovic, J. Comparative kinetic analysis of total hypericin extraction from Hypericum perforatum flowers carried out under simultaneous external physical field and cooling reaction system operational conditions. Chem. Eng. Res. Des. 2020, 165, 106-117. [CrossRef]

30. Napoli, E.; Siracusa, L.; Ruberto, G.; Carrubba, A.; Lazzara, S.; Speciale, A.; Cimino, F.; Saija, A.; Cristani, M. Phytochemical profiles, phototoxic and antioxidant properties of eleven Hypericum species-A comparative study. Phytochemistry 2018, 152, 162-173. [CrossRef]

31. Nazlı, O.; Baygar, T.; Dönmez, E.D.; Dere, Ö.; Uysal, A.I.; Aksozek, A.; Işık, C.; Aktürk, S. Antimicrobial and antibiofilm activity of polyurethane/Hypericum perforatum extract (PHPE) composite. Bioorganic. Chem. 2018, 82, 224-228. [CrossRef] [PubMed]

32. Pradeep, M.; Kachlicki, P.; Franklin, G. Simultaneous determination of naphtodianthrones, emodin, skyrin and new bisanthrones in Hypericum perforatum L. in vitro shoot cultures. Ind. Crop. Prod. 2019, 144, 112003. [CrossRef]

33. Şengün, D.N.; Karaca, I.R.; Saraç, N.; Uğur, A.; Fırat, A.; Kaymaz, F.F.; Öztürk, H.S. Evaluation of the chemopreventive effects of Hypericum perforatum L. on DMBA-applied rat oral mucosa. Arch. Oral Biol. 2021, 127, 105139. [CrossRef]

34. Carrubba, A.; Lazzara, S.; Giovino, A.; Ruberto, G.; Napoli, E. Content variability of bioactive secondary metabolites in Hypericum perforatum L. Phytochem. Lett. 2021, 46, 71-78. [CrossRef]

35. Radulović, N.S.; Genčić, M.S.; Stojanović, N.M.; Randjelović, P.J.; Baldovini, N.; Kurteva, V. Prenylated $\beta$-diketones, two new additions to the family of biologically active Hypericum perforatum L. (Hypericaceae) secondary metabolites. Food Chem. Toxicol. 2018, 118, 505-513. [CrossRef] [PubMed]

36. Ramalhete, N.; Machado, A.; Serrano, R.; Gomes, E.T.; Mota-Filipe, H.; Silva, O. Comparative study on the in vivo antidepressant activities of the Portuguese Hypericum foliosum, Hypericum androsaemum and Hypericum perforatum medicinal plants. Ind. Crop. Prod. 2015, 82, 29-36. [CrossRef]

37. Bálintová, M.; Bruňáková, K.; Petijová, L.; Čellárová, E. Targeted metabolomic profiling reveals interspecific variation in the genus Hypericum in response to biotic elicitors. Plant. Physiol. Biochem. 2019, 135, 348-358. [CrossRef]

38. Becker, L.; Zaiter, A.; Petit, J.; Zimmer, D.; Karam, M.-C.; Baudelaire, E.; Scher, J.; Dicko, A. Improvement of antioxidant activity and polyphenol content of Hypericum perforatum and Achillea millefolium powders using successive grinding and sieving. Ind. Crop. Prod. 2016, 87, 116-123. [CrossRef]

39. He, M.; Wang, Z. Genetic diversity of Hypericum perforatum collected from the Qinling Mountains of China. Biochem. Syst. Ecol. 2013, 50, 232-239. [CrossRef]

40. Tocci, N.; Weil, T.; Perenzoni, D.; Narduzzi, L.; Madriñán, S.; Crockett, S.; Nürk, N.M.; Cavalieri, D.; Mattivi, F. Phenolic profile, chemical relationship and antifungal activity of Andean Hypericum species. Ind. Crop. Prod. 2018, 112, 32-37. [CrossRef]

41. Zhang, J.; Feng, C.; Xu, H.; Tan, X.; Hagedoorn, P.-L.; Ding, S. Enhanced hypericin extraction from Hypericum perforatum L. by coupling microwave with enzyme-assisted strategy. Ind. Crop. Prod. 2019, 137, 231-238. [CrossRef]

42. Zhang, R.; Ji, Y.; Morcol, T.; Lin, F.; Gu, R.; Kennelly, E.J.; Long, C. UPLC-QTof-MS chemical profiling and characterization of antiproliferative and anti-inflammatory compounds from seven Hypericum species in China. Ind. Crop. Prod. 2021, 173, 114156. [CrossRef] 
43. Sharma, S.; Walia, S.; Rathore, S.; Kumar, P.; Kumar, R. Combined effect of elevated $\mathrm{CO}_{2}$ and temperature on growth, biomass and secondary metabolite of Hypericum perforatum L. in a western Himalayan region. J. Appl. Res. Med. Aromat. Plants 2019, 16, 100239. [CrossRef]

44. Cirak, C.; Radušienè, J.; Kurtarc, E.; Marksa, M.; Ivanauskas, L. In vitro plant regeneration and jasmonic acid induced bioactive chemical accumulations in two Hypericum species from Turkey. S. Afr. J. Bot. 2019, 128, 312-318. [CrossRef]

45. Cirak, C.; Radusiene, J.; Jakštas, V.; Ivanauskas, L.; Seyis, F.; Yayla, F. Altitudinal changes in secondary metabolite contents of Hypericum androsaemum and Hypericum polyphyllum. Biochem. Syst. Ecol. 2017, 70, 108-115. [CrossRef]

46. Gitea, D.; Vicas, S.; Gitea, M.A.; Nemeth, S.; Tit, D.M.; Pasca, B.; Purza, L.; Iovan, C.V. HPLC Screening of Bioactives Compounds and Antioxidant Capacity of Different Hypericum Species. Rev. Chim. 2018, 69, 305-309. [CrossRef]

47. Seyis, F.; Yurteri, E.; Özcan, A.; Cirak, C. Altitudinal impacts on chemical content and composition of Hypericum perforatum, a prominent medicinal herb. S. Afr. J. Bot. 2020, 135, 391-403. [CrossRef]

48. Zeliou, K.; Koui, E.-M.; Papaioannou, C.; Koulakiotis, N.S.; Iatrou, G.; Tsarbopoulos, A.; Papasotiropoulos, V.; Lamari, F.N Metabolomic fingerprinting and genetic discrimination of four Hypericum taxa from Greece. Phytochemistry 2020, 174, 112290. [CrossRef] [PubMed]

49. Tahmasebi-Boldaji, R.; Hatamipour, M.-S.; Khanahmadi, M.; Sadeh, P.; Najafipour, I. Ultrasound-assisted packed-bed extraction of hypericin from Hypericum perforatum L. and optimization by response surface methodology. Ultrason. Sonochemistry 2019, 57, 89-97. [CrossRef]

50. Lou, H.; Yi, P.; Hu, Z.; Li, Y.; Zeng, Y.; Gu, W.; Huang, L.; Yuan, C.; Hao, X. Polycyclic polyprenylated acylphloroglucinols with acetylcholinesterase inhibitory activities from Hypericum perforatum. Fitoterapia 2020, 143, 104550. [CrossRef] [PubMed]

51. Mandrone, M.; Scognamiglio, M.; Fiorentino, A.; Sanna, C.; Cornioli, L.; Antognoni, F.; Bonvicini, F.; Poli, F. Phytochemical profile and $\alpha$-glucosidase inhibitory activity of Sardinian Hypericum scruglii and Hypericum hircinum. Fitoterapia 2017, 120, 184-193. [CrossRef]

52. Bruňáková, K.; Čellárová, E. Modulation of anthraquinones and phloroglucinols biosynthesis in Hypericum spp. by cryogenic treatment. J. Biotechnol. 2017, 251, 59-67. [CrossRef]

53. Doğan, Ş.; Gökalsın, B.; Şenkardeş, İ; Doğan, A.; Sesal, N.C. Anti-quorum sensing and anti-biofilm activities of Hypericum perforatum extracts against Pseudomonas aeruginosa. J. Ethnopharmacol. 2019, 235, 293-300. [CrossRef]

54. Singh, P.; Kaufholdt, D.; Awadalah, M.; Hänsch, R.; Beerhues, L.; Gaid, M. Cytosolic aromatic aldehyde dehydrogenase provides benzoic acid for xanthone biosynthesis in Hypericum. Plant Physiol. Biochem. 2021, 160, 82-93. [CrossRef] [PubMed]

55. Jafarirad, S.; Kosari-Nasab, M.; Tavana, R.M.; Mahjouri, S.; Ebadollahi, R. Impacts of manganese bio-based nanocomposites on phytochemical classification, growth and physiological responses of Hypericum perforatum L. shoot cultures. Ecotoxicol. Environ. Saf. 2020, 209, 111841. [CrossRef] [PubMed]

56. Jarzębski, M.; Smułek, W.; Baranowska, H.M.; Masewicz, Ł.; Kobus-Cisowska, J.; Ligaj, M.; Kaczorek, E. Characterization of St. John's wort (Hypericum perforatum L.) and the impact of filtration process on bioactive extracts incorporated into carbohydratebased hydrogels. Food Hydrocoll. 2020, 104, 105748. [CrossRef]

57. Karakashov, B.; Grigorakis, S.; Loupassaki, S.; Makris, D.P. Optimisation of polyphenol extraction from Hypericum perforatum (St. John's Wort) using aqueous glycerol and response surface methodology. J. Appl Res. Med. Aromat. Plants 2015, 2, 1-8. [CrossRef]

58. Barros, F.M.; Pippi, B.; Dresch, R.R.; Dauber, B.; Luciano, S.C.; Apel, M.A.; Fuentefria, A.; von Poser, G.L. Antifungal and antichemotactic activities and quantification of phenolic compounds in lipophilic extracts of Hypericum spp. native to South Brazil. Ind. Crop. Prod. 2012, 44, 294-299. [CrossRef]

59. Ccana-Ccapatinta, G.V.; Kaiser, S.; Danielli, L.J.; Dresch, R.R.; D’Avila, F.B.; Fröehlich, P.E.; Ortega, G.G.; Apel, M.A.; Von Poser, G.L. Acylphloroglucinol profile and antichemotactic activity of lipophilic extracts from Peruvian Hypericum species. Ind. Crop. Prod. 2018, 125, 323-327. [CrossRef]

60. da Conceição, A.O.; von Poser, G.L.; Barbeau, B.; Lafond, J. Hypericum caprifoliatum and Hypericum connatum affect human trophoblast-like cells differentiation and Ca2+ influx. Asian Pac. J. Trop Biomed. 2014, 4, 367-373. [CrossRef]

61. Dagnino, A.P.; de Barros, F.M.C.; Ccana-Ccapatinta, G.V.; Prophiro, J.S.; von Poser, G.L.; Romão, P.R. Leishmanicidal activity of lipophilic extracts of some Hypericum species. Phytomedicine 2015, 22, 71-76. [CrossRef]

62. Gaid, M.; Haas, P.; Beuerle, T.; Scholl, S.; Beerhues, L. Hyperforin production in Hypericum perforatum root cultures. J. Biotechnol. 2016, 222, 47-55. [CrossRef]

63. Heinrich, M.; Vikuk, V.; Daniels, R.; Stintzing, F.C.; Kammerer, D.R. Characterization of Hypericum perforatum L. (St. John's wort) macerates prepared with different fatty oils upon processing and storage. Phytochem. Lett. 2017, 20, 470-480. [CrossRef]

64. Eroglu, E.; Girgin, S.N. A unique phenolic extraction method from olive oil macerate of Hypericum perforatum using DMSO: Assessment of in vitro anticancer activity, LC-MS/MS profile, total phenolic content and antioxidant capacity. S. Afr. J. Bot. 2021, 139, 6-11. [CrossRef]

65. Yücel, A.; Kan, Y.; Yesilada, E.; Akın, O. Effect of St. John's wort (Hypericum perforatum) oily extract for the care and treatment of pressure sores; a case report. J. Ethnopharmacol. 2017, 196, 236-241. [CrossRef]

66. Hosni, K.; Msaâda, K.; Ben Taârit, M.; Marzouk, B. Fatty acid composition and tocopherol content in four Tunisian Hypericum species: Hypericum perforatum, Hypericum tomentosum, Hypericum perfoliatum and Hypericum ericoides ssp. Roberti. Arab. J. Chem. 2017, 10, S2736-S2741. [CrossRef] 
67. Abdelhadi, M.; Meullemiestre, A.; Gelicus, A.; Hassani, A.; Rezzoug, S.-A. Intensification of Hypericum perforatum L. oil isolation by solvent-free microwave extraction. Chem. Eng. Res. Des. 2015, 93, 621-631. [CrossRef]

68. Sakavitsi, M.-E.; Christodoulou, M.-I.; Tchoumtchoua, J.; Fokialakis, N.; Kokkinopoulou, I.K.; Papageorgiou, E.; Argyropoulou, A.; Skaltsounis, L.A.; Halabalaki, M.; Scorilas, A. Comparative HPLC-DAD and UHPLC-ESI(-)-HRMS \& MS/MS profiling of Hypericum species and correlation with necrotic cell-death activity in human leukemic cells. Phytochem. Lett. 2017, $20,481-490$. [CrossRef]

69. Strzemski, M.; Dresler, S.; Sowa, I.; Kurach, Ł.; Kováčik, J.; Wojas-Krawczyk, K.; Wójciak, M. Direct spectroscopic and GC profiling combined with chemometric analysis as an alternative approach to investigate Hypericum species: Is it possible to replace HPLC? Ind. Crops Prod. 2020, 157, 112930. [CrossRef]

70. Mohammadi, G.; Rafiee, G.; El Basuini, M.F.; Van Doan, H.; Ahmed, H.A.; Dawood, M.A.; Abdel-Latif, H.M. Oregano (Origanum vulgare), St John's-wort (Hypericum perforatum), and lemon balm (Melissa officinalis) extracts improved the growth rate, antioxidative, and immunological responses in Nile tilapia (Oreochromis niloticus) infected with Aeromonas hydrophil. Aquac. Rep. 2020, 18, 100445. [CrossRef]

71. Haas, P.; Gaid, M.; Zarinwall, A.; Beerhues, L.; Scholl, S. Downstream processing of hyperforin from Hypericum perforatum root cultures. Eur. J. Pharm. Biopharm. 2018, 126, 104-107. [CrossRef]

72. Tocci, N.; D’Auria, F.D.; Simonetti, G.; Panella, S.; Palamara, A.T.; Debrassi, A.; Rodrigues, C.A.; Filho, V.C.; Sciubba, F.; Pasqua, G. Bioassay-guided fractionation of extracts from Hypericum perforatum in vitro roots treated with carboxymethylchitosans and determination of antifungal activity against human fungal pathogens. Plant Physiol. Biochem. 2013, 70, 342-347. [CrossRef]

73. Bertoli, A.; Çirak, C.; Seyis, F. Hypericum spp. volatile profiling and the potential significance in the quality control of new valuable raw material. Microchem. J. 2018, 136, 94-100. [CrossRef]

74. Đorđević, A.; Lazarević, J.; Šmelcerović, A.; Stojanović, G. The case of Hypericum rochelii Griseb. \& Schenk and Hypericum umbellatum A. Kern. essential oils: Chemical composition and antimicrobial activity. J. Pharm. Biomed. Anal. 2013, 77, 145-148. [CrossRef] [PubMed]

75. Khorshidi, J.; Morshedloo, M.R.; Moradi, S. Essential oil composition of three Iranian Hypericum species collected from different habitat conditions. Biocatal. Agric. Biotechnol. 2020, 28, 101755. [CrossRef]

76. Morshedloo, M.R.; Ebadi, A.; Maggi, F.; Fattahi, R.; Yazdani, D.; Jafari, M. Chemical characterization of the essential oil compositions from Iranian populations of Hypericum perforatum L. Ind. Crop. Prod. 2015, 76, 565-573. [CrossRef]

77. Ortega-Puma, C.; Fajardo-Carmona, S.; Ortíz-Ulloa, J.; Tobar, V.; Quito-Ávila, D.; Santos-Ordoñez, E.; Jerves-Andrade, L.; Cuzco, N.; Wilches, I.; León-Tamaríz, F. Evaluation of the variables altitude, soil composition and development of a predictive model of the antibacterial activity for the genus Hypericum by chromatographic fingerprint. Phytochem. Lett. 2019, 31, 104-113. [CrossRef]

78. Zhang, J.; Feng, C.; Ge, P.; Wang, Q.; Liu, Y.; Xu, H.; Zhou, X. High purity separation of hypericin from Hypericum perforatum L. extract with macroporous resin column coupling preparative liquid chromatography. Process Biochem. 2021, 103, 107-113. [CrossRef]

79. de Carvalho Meirelles, G.; Bridi, H.; Rates, S.M.K.; von Poser, G.L. Southern Brazilian Hypericum Species, Promising Sources of Bioactive Metabolites, 1st ed.; Studies in Natural Products Chemistry; Elsevier B.V.: Amsterdam, The Netherlands, 2018; Volume 59, pp. 491-507.

80. Eray, N.; Dalar, A.; Turker, M. The effects of abiotic stressors and signal molecules on phenolic composition and antioxidant activities of in vitro regenerated Hypericum perforatum (St. John's Wort). S. Afr. J. Bot. 2020, 133, 253-263. [CrossRef]

81. Yao, Y.; Kang, T.; Jin, L.; Liu, Z.; Zhang, Z.; Xing, H.; Sun, P.; Li, M. Temperature-dependent growth and hypericin biosynthesis in Hypericum perforatum. Plant Physiol. Biochem. 2019, 139, 613-619. [CrossRef] [PubMed]

82. Li, Z.; Qin, C.; Li, D.; Hou, Y.; Li, S.; Sun, J. Molecularly imprinted polymer for specific extraction of hypericin from Hypericum perforatum L. herbal extract. J. Pharm. Biomed. Anal. 2014, 98, 210-220. [CrossRef]

83. Council of Europe. Hyperici herbae extractum siccum quantificatum. Eur. Pharmacopoeia. 2013, 8, $1391-1395$.

84. Pellegrini, E.; Campanella, A.; Cotrozzi, L.; Tonelli, M.; Nali, C.; Lorenzini, G. Ozone primes changes in phytochemical parameters in the medicinal herb Hypericum perforatum (St. John's wort). Ind. Crop. Prod. 2018, 126, 119-128. [CrossRef]

85. Belwal, T.; Devkota, H.P.; Singh, M.K.; Sharma, R.; Upadhayay, S.; Joshi, C.; Bisht, K.; Gour, J.K.; Bhatt, I.D.; Rawal, R.S.; et al. St. John's Wort (Hypericum perforatum). In Nonvitamin and Nonmineral Nutritional Supplements; Elsevier Inc.: Amsterdam, The Netherlands, 2018; pp. 415-432.

86. Bridi, H.; de Carvalho Meirelles, G.; von Poser, G.L. Structural diversity and biological activities of phloroglucinol derivatives from Hypericum species. Phytochemistry 2018, 155, 203-232. [CrossRef]

87. Huck, C.; Abel, G.; Popp, M.; Bonn, G. Comparative analysis of naphthodianthrone and phloroglucine derivatives in St. John's Wort extracts by near infrared spectroscopy, high-performance liquid chromatography and capillary electrophoresis. Anal. Chim. Acta 2006, 580, 223-230. [CrossRef]

88. Filippini, R.; Piovan, A.; Borsarini, A.; Caniato, R. Study of dynamic accumulation of secondary metabolites in three subspecies of Hypericum perforatum. Fitoterapia 2010, 81, 115-119. [CrossRef]

89. Temerdashev, Z.; Milevskaya, V.; Shpigun, O.; Prasad, S.; Vinitskaya, E.; Ryaboko, L. Stability of some biologically active substances in extracts and preparations based on St. John's wort (Hypericum perforatum L.) And sage (Salvia officinalis L.). Ind. Crop. Prod. 2020, 156, 112879. [CrossRef]

90. Klejdus, B.; Kováčik, J.; Babula, P. PAL inhibitor evokes different responses in two Hypericum species. Plant Physiol. Biochem. 2013, 63, 82-88. [CrossRef] [PubMed] 
91. Kováčik, J.; Klejdus, B.; Bačkor, M. Nitric oxide signals ROS scavenger-mediated enhancement of PAL activity in nitrogen-deficient Matricaria chamomilla roots: Side effects of scavengers. Free. Radic. Biol. Med. 2009, 46, 1686-1693. [CrossRef] [PubMed]

92. Fiesel, T.; Gaid, M.; Müller, A.; Bartels, J.; El-Awaad, I.; Beuerle, T.; Ernst, L.; Behrends, S.; Beerhues, L. Molecular cloning and characterization of a xanthone prenyltransferase from Hypericum calycinum cell cultures. Molecules 2015, 20, 15616-15630. [CrossRef] [PubMed]

93. Nagia, M.; Gaid, M.; Biedermann, E.; Fiesel, T.; El-Awaad, I.; Hänsch, R.; Wittstock, U.; Beerhues, L. Sequential regiospecific gem-diprenylation of tetrahydroxyxanthone by prenyltransferases from Hypericum sp. New Phytol. 2018, 222, 318-334. [CrossRef] [PubMed]

94. Booker, A.; Agapouda, A.; Frommenwiler, D.A.; Scotti, F.; Reich, E.; Heinrich, M. St John's wort (Hypericum perforatum) products -An assessment of their authenticity and quality. Phytomedicine 2018, 40, 158-164. [CrossRef]

95. Liu, Y.-R.; Li, W.-G.; Chen, L.-F.; Xiao, B.-K.; Yang, J.-Y.; Yang, L.; Zhang, C.-G.; Huang, R.-Q.; Dong, J.-X. ABTS+ scavenging potency of selected flavonols from Hypericum perforatum L. by HPLC-ESI/MS QQQ: Reaction observation, adduct characterization and scavenging activity determination. Food Res. Int. 2014, 58, 47-58. [CrossRef]

96. Babula, P.; Klejdus, B.; Kovacik, J.; Hedbavny, J.; Hlavna, M. Lanthanum rather than cadmium induces oxidative stress and metabolite changes in Hypericum perforatum. J. Hazard. Mater. 2015, 286, 334-342. [CrossRef] [PubMed]

97. Helmja, K.; Vaher, M.; Püssa, T.; Orav, A.; Viitak, A.; Levandi, T.; Kaljurand, M. Variation in the composition of the essential oils, phenolic compounds and mineral elements of Hypericum perforatum L. growing in Estonia. Nat. Prod. Res. 2011, 25, 496-510. [CrossRef] [PubMed]

98. Coppock, R.W.; Dziwenka, M. St. John's Wort, Nutraceuticals Efficacy Safe Toxicity; Elsevier Inc.: Amsterdam, The Netherlands, 2016; pp. 619-661.

99. Sun, P.; Kang, T.; Xing, H.; Zhang, Z.; Yang, D.; Zhang, J.; Paré, P.W.; Li, M. Phytochemical Changes in Aerial Parts of Hypericum perforatum at Different Harvest Stages. Rec. Nat. Prod. 2019, 13, 1-9. [CrossRef]

100. Owen, J.D.; Kirton, S.B.; Evans, S.J.; Stair, J.L. Elemental fingerprinting of Hypericum perforatum (St. John's Wort) herb and preparations using ICP-OES and chemometrics. J. Pharm. Biomed. Anal. 2016, 125, 15-21. [CrossRef]

101. Gîtea, D. Specii de Hypericum in Terapie; Editura Universităţii din Oradea: Oradea, Romania, 2015.

102. Raclariu-Manolica, A.C.; Paltinean, R.; Vlase, L.; Labarre, A.; Manzanilla, V.; Ichim, M.C.; Crisan, G.; Brysting, A.K.; De Boer, H. Comparative authentication of Hypericum perforatum herbal products using DNA metabarcoding, TLC and HPLC-MS. Sci. Rep. 2017, 7, 1-12. [CrossRef] 